\title{
The RENAPE observational registry: rationale and framework of the rare peritoneal tumors French patient registry
}

L. Villeneuve ${ }^{1,2,7^{*}}$, G. Passot ${ }^{2,3}$, O. Glehen ${ }^{2,3}$, S. Isaac ${ }^{2,4}$, F. Bibeau ${ }^{5}$, P. Rousset ${ }^{2,6}$, F. N. Gilly $y^{2,3}$ and on behalf of the RENAPE Network

\begin{abstract}
Background: Rare peritoneal cancers represent complex clinical situations requiring a specific and multidisciplinary management. Because of their rarity, lack of awareness and knowledge often leads to diagnostic delays and misdiagnosis. And patients are not systematically referred to expert centers as they should be. Clinicians and researchers also face unique challenges with these rare cancers, because it is hard to conduct adequately powered, controlled trials in such small patient population. This is how an observational patient registry constitutes a key instrument for the development of epidemiological and clinical research in the field of these rare cancers. It is the appropriate tool to pool scarce data for epidemiological research and to assess the impact of diagnostic and therapeutic strategies. We aimed to provide the outlines and the framework of the RENAPE observational registry and share our experience in the establishment of a national patient registry.
\end{abstract}

Results: The RENAPE observational registry has been launched in 2010 thanks to institutional supports. It concerns only patients with a histological diagnosis confirming a peritoneal surface malignancy. A web secured clinical database has been implemented based on data management procedures according to the principles of international recommendations and regulatory statements. A virtual tumor bank is linked in order to the conduct translational studies. Specialized working groups have been established to continuously upgrade and evolve the common clinical and histological data elements following the last classifications and clinical practices. They contribute also to standardize clinical assessment and homogenize practices.

Conclusions: The RENAPE Registry may improve awareness and understanding of the rare peritoneal tumors into the incidence, prevalence, recurrence, survival and mortality rates, as well as treatment practices thereby enabling therapeutic intervention to be evaluated and ultimately optimized.

Trial registration: ClinicalTrials.gov Identifier: NCT02834169

Keywords: Rare cancer network, Patient registry, Rare peritoneal tumor, Pseudomyxoma peritonei, Peritoneal mesothelioma

\footnotetext{
* Correspondence: laurent.villeneuve@chu-lyon.fr

${ }^{1}$ Hospices Civils de Lyon, Pôle Information Médicale Evaluation Recherche,

Unité de Recherche Clinique, Lyon, France

EMR 3738, Lyon 1 University, Lyon, France

Full list of author information is available at the end of the article
} 


\section{Background}

Peritoneal carcinomatosis most commonly represents local or regional evolution of an abdominal carcinoma. Sometimes it can be synchronous with the primary tumor (primary carcinomatosis) but more often is present as recurrent disease (metachronous or secondary) after first-line treatment of the primary tumor. When peritoneal masses are discovered, the principal diagnostic concern is metastatic disease, which is the most frequently encountered neoplastic process that involves the peritoneal cavity. However, primary peritoneal tumors should be appropriately included in the differential diagnosis in patients presenting with diffuse or focal peritoneal disease processes. Primary peritoneal tumors are an uncommon group of diverse pathologic disorders that share a common anatomic site of origin and have overlapping imaging features, yet are distinctly different clinically. Tumors originating from the peritoneum itself are definitely rarer and represent complex clinical situations requiring a specific management in expert centers. Differentiating primary peritoneal tumors from metastatic disease is important clinically so that patient management is appropriate. An epidemiological surveillance based on a specific tool is needed to better understand their characteristics and evolve the standards of care.

\section{Pseudomyxoma peritonei}

Pseudomyxoma peritonei (PMP) is an uncommon clinical entity with an estimated incidence of one to two per million per year worldwide. According to national data based on population, the annual incidence of PMP is 1,500 cases in the United States of America (USA) and approximately 27 cases or 1.7 to 2 per million per year in the Netherlands. The incidence in Asia is about one per million per year and is presumed to be about a quarter of that in USA [1]. The occurrence of PMP is slightly higher in women than in men [2-4]. PMP occurs in approximately two of every 10,000 laparotomies and is more common in women with an average age of 53 years [2]. PMP is characterized by a gelatinous ascite associated with mucinous tumor deposits spreading on peritoneal surface and potentially invading abdominal organs [5]. PMP generally originates from a perforated appendiceal tumor. The biology of the disease is poorly understood and no overall consensus exists on histopathological classification, although tumors are commonly classified in a binary classification into Low grade appendiceal mucinous neoplasm (LAMN) or high grade mucinous adenocarcinoma [6-8]. The current standard of care with curative intent involves a combination of complete cytoreductive surgery (CRS) with hyperthermic intraperitoneal chemotherapy (HIPEC) $[9,10]$. The treatment strategy is complex, associated with significant morbidity and mortality and a substantial institutional, and surgical "learning curve" $[11,12]$. For selected patients, it results in long term survival and cure [9, 13-15].

\section{Peritoneal mesothelioma}

Peritoneal Mesothelioma (PM) is a rare malignancy [16]. The incidence rates (per 1,000,000) range between 0.5 and three cases in men and between 0.2 and two cases in women [16]. A review of non-pleural mesotheliomas using data from surveillance, epidemiology and end results (SEER) estimated that mesothelioma numbers are about 2,500 per year in USA, with peritoneal being about $10-20 \%$ [17]. There is a predominance in the male population with a sex ratio of 3:1 (male:female) [16, 18]. The median age at diagnosis ranges from 49 to 55.7 years [19]. Occupational and environmental asbestos exposure seems to be causative in some cases of PM [20, 21]. Other even less frequent associations have been reported as implicated factors favoring the development of the PM as radiation therapy, SV 40 virus, chronic peritonitis, thorium dioxide or mica exposure $[19,22-25]$. PM is locally aggressive neoplasm that comprises low-grade variants, such as multicystic and papillary well-differentiated mesothelioma, and highly malignant counterparts [26]. PM is confined to the serosal surface of the peritoneal cavity from the mesothelial cells overlying peritoneum. It has long been considered a preterminal condition amenable only to palliative treatment with a historical median survival of less than 12 months [22]. Over the past decades, the combined approach of extensive CRS and HIPEC has emerged as a therapeutic modality for this disease and is admitted as the standard of treatment offering the longest survival and cure [27-33].

\section{Primary peritoneal serous carcinoma}

Primary peritoneal serous carcinoma (PPSC) is a rare condition compared to their ovarian counterpart (6 vs. 120 women cases per million respectively) [34]. PPSC is an extra-ovarian primary peritoneal malignancy, histologically identical and clinically similar to advanced stage serous ovarian carcinoma. PPSC can occur many years after ovary removal surgery performed for benign diseases or prophylactic oophorectomy. The tumor appears during adulthood with a median age at diagnosis of 62 years [35, 36]. Women with breast cancer type 1 (BRCA1) gene mutations present an increased risk of developing a PPSC [35]. The therapeutic approach combining CRS with HIPEC has recently demonstrated a survival benefit in patients with PPSC when compared to those treated with surgery alone or surgery in combination with systemic chemotherapy [37].

\section{Peritoneal desmoplastic small round cell tumors}

Desmoplastic small round cell tumor (DSRCT) is a rare abdominal tumor but highly fatal malignancy with only approximately 450 cases described in the literature (among which more than 60 are case reports) since its first description in 1991 by Gerald et al. [38, 39]. No large population data exists regarding the epidemiology of this tumor due to its rarity. Previous studies reported 
that DSRCT was found to be more prevalent in males [40]. This tumor type has a strong tendency to spread within the peritoneum but can also give rise to extraperitoneal metastases, mainly in the liver and lungs $[39,41]$. A unique chromosomal translocation $\mathrm{t}(11 ; 32)(\mathrm{p} 13 ; \mathrm{q} 12)$, of the Ewing sarcoma gene breakpoint region 1 (EWSR1) on 22q13 and the Wilms tumor gene (WT1) on chromosome $11 \mathrm{p} 13$ is highly specific and allows a formal diagnosis of DSRCT [42]. Without large series in the literature, standard of care for treatment of DSRCT remains unclear and challenging. However a multimodality approach with chemotherapy, surgery and radiotherapy appears to represent optimal management [39].

\section{Diffuse peritoneal leiomyomatosis}

Diffuse peritoneal leiomyomatosis (DPL) is rare disease. Fewer than 150 cases have been reported in the literature to date. DPL is characterized by the proliferation of multiple benign smooth muscle cell-containing nodules in the peritoneal cavity. DPL manifests during adulthood and is predominantly found in women. Only one case of DPL has been reported in a male [43]. Malignant transformation is rare and in a few cases [44]. Etiology is unknown but DPL seems to be a multifactorial disease with a genetic or hormonal component leading to metaplasia of peritoneal mesenchymal cells $[45,46]$. Depending on the extent of the disease, first-line treatment for DPL is surgical excision or CRS [47].

The establishment of a the French network for rare peritoneal tumors (RENAPE) reference networks with a clinical database linked to a virtual tissue bank aims to improve outcomes and make easier the exchange of experience, information, data and best practices on rare peritoneal malignancies (RPM) amongst all stakeholders [48]. Because of establishing a patient registry is a complex process which requires a range of technical and organizational skills; this paper aims to provide a framework for the implementation of a patient registry in the field of RPM and includes the important aspects that need attention during this process.

\section{Methods}

\section{Objectives and scope}

By definition, a registry is "an organized system that uses observational study methods to collect uniform data (clinical and others) from individual patient to evaluate specified outcomes for a population defined by a particular disease, condition or exposure, and that serves one or more predetermined scientific, clinical, or policy purposes" [49]. The RENAPE Registry has been launched in 2010. It aims to monitor more prevalence and incidence of RPM in France, to establish natural history of these rare cancers. It is also intended to assess the clinical effectiveness of new interventions, to measure the quality of care and to provide an inventory of patients to re-contact for participation in epidemiological studies, clinical trials or for health technology assessment to monitor real access to treatments.

\section{Institutional support}

The RENAPE Observational Registry benefits the full support of the national patients association against RPM (AMARAPE) and is endorsed by French National Cancer Institute (INCa) as a global priority in the field of Rare Cancer. It is also partner of the European Platform for Rare Disease Registries (EPIRARE) co-funded by the European Commission within the European Union Program of Community Action in the field of Public Health.

\section{Ethical and legal statements}

The RENAPE Observational Registry complies with applicable local regulations and with the ethical principles laid down in the Declaration of Helsinki (Fortaleza 2013). The RENAPE Observational Registry has been approved by the Advisory Committee for Data Processing in Health Research at the Research French Ministry (CCTIRS $\left.n^{\circ} 10.257\right)$. The RENAPE Observational Registry has been registered with French Data Protection Authority (CNIL - no. DR-2010-297) in accordance with the French Law 78-17 dated January 6th, 1978 relating to data processing, files and personal freedom and privacy.

\section{Patient population}

The RENAPE Observational Registry includes only patients with RPM such as peritoneal mesothelioma (ORPHA168811/168816), pseudomyxoma peritonei (ORPHA26790), primary peritoneal serous carcinoma (ORPHA168829), peritoneal desmoplastic small round cell tumors (ORPHA83469), diffuse peritoneal leiomyomatosis (ORPHA71274). All patients were required a confirmation of histological diagnosis as determined by an expert pathologist [48]. The RENAPE Observational Registry database concerns only persons whose usual place of residence is France.

\section{Registry design}

The RENAPE Observational Registry is a retrospective, longitudinal patient registry that has been implemented through a secure, fully Web-based application $\left(\mathrm{EOL}^{\circ}\right)$. It has been launched as an open-ended project without a pre-defined stopping point. The access to the registry application has currently been opened at all specialized French centers with expertise in the treatment of RPM [48]. 


\section{Data entry and management}

For each new patient a minimal data set is required (Table 1) including identification, demographic information and etiology. The RENAPE Observational Registry employs internal record linkage to identify and eliminate duplicate patient and tumor records. Each entry in the registry has a unique identifier (alphanumeric code). Identification codes are stored in an independent and safe database according to the French Data Protection Act. Patients are written and oral informed that a pseudonymisation method replacing any identifying characteristics of registered personal data with a pseudonym (alphanumeric code) provides a limited protection for the identity of data subjects. However all aggregated data or results provided from the registered data are strictly anonymous. The clinical data capture will be updated appropriately based on each patient's clinical management. Clinical data are directly collected in a standard format by the clinicians. A resource person - a clinical research assistant - with specialized knowledge in the clinical pathways of the RPM - is provided by the coordination of the RENAPE Registry in order to help sites on data entry process. The RENAPE Registry common data elements are organized into 9 categories: patient information, preoperative work-up, peroperative data and 90-day postoperative follow-up (Table 2) and long term follow-up. We use preferentially appropriate scores (Peritoneal Cancer Index PCI, completeness of cytoreduction score - CC-score) and validated classifications (CTCAE). Clear, operational definitions of data elements and standard instructions were provided to collect data consistently. At each participating site, a local pathologist validates and records histological subtype and grade of tumor on extended data set available to capture pathological details (Table 3). Correlation edits check the compatibility of different data elements within a record. These verifications are done as data are loaded into the database and any records failing edits are rejected and

\section{Table 1 Minimum data set}

\begin{tabular}{l}
\hline Identification \\
Surname \\
Birth name \\
Name \\
Demographics \\
Birth date \\
Sex \\
Etiology \\
Peritoneal mesothelioma \\
Pseudomyxoma peritonei \\
Primary peritoneal serous carcinoma \\
Peritoneal desmoplastic small round cell tumors \\
Diffuse peritoneal leiomyomatosis \\
\hline
\end{tabular}

returned to the participating sites for verification and/ or correction. The data management procedures follow in accordance with the principles of Good Clinical Practices (GCP). The scope of these standard operating procedures is to: staff training and qualifications, case inclusion, case ascertainment, procedures for adding new cases to the permanent data set, rules for updating or changing data on file, follow-up, data exchange. Data quality is assured by pre-testing and consistency checks during data entry, when applicable. Data originate from various sources and specific attention is taken to avoid duplicate information.

\section{Data protection}

The $\mathrm{EOL}^{\odot}$ application is validated under 21 Code of Federal Regulations criteria (CFR Part 11) [50]. Data protection is based on the definition of authorization profiles, defining the functions or types of information available to a user. The access to the electronic data capture application is controlled by personal username and password generated by the administrator. All recorded data must be validated by electronic signature. An audit trail module allows tracking of all accesses, modifications, and deletions of data. All exported files are archived with history within the system. The automatic identification of patients without nominative data enables an interoperability of the data recorded and remains pseudonymous. The RENAPE Registry benefits of a safe and secure hosting in France based on Information Technology Infrastructure Library (ITIL) security management (version 3 ).

\section{Follow up data}

The RENAPE registry devotes substantial efforts to engage participating physicians in the registry to minimize and monitor loss to follow-up. If the patient has returned to the facility, records are obtained and appropriate information extracted. Physicians route the record to the RENAPE Registry coordination team. If the patient has not returned to the institution, follow-up letters are usually mailed to the managing or referring physician. Letters may be sent to other physicians involved in the care of the patient. A date of last contact should be requested in the letter for the patient or contact to complete (Table 4).

\section{Results and discussion}

Rare cancer patient registries as the RENAPE Registry represent a fundamental research tool for increasing knowledge on rare cancers by pooling data for fundamental and clinical research, epidemiological research. Patient registries and databases constitute key instruments for the development of clinical research in the field of rare cancers such RPM. They are the appropriate way to conduct research on populations and conditions that are not generally studied in 
Table 2 Common clinical data elements

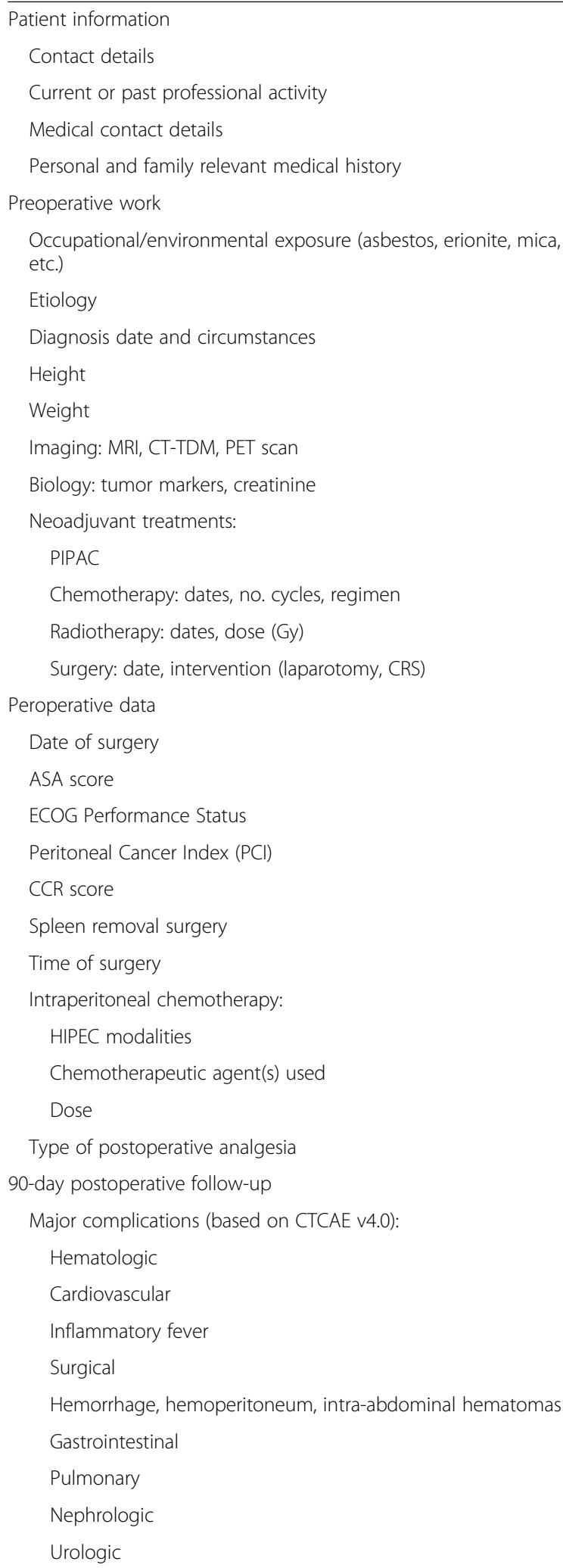

Table 2 Common clinical data elements (Continued)

\author{
Re-intervention (surgery) \\ Image-guided drainage \\ Endoscopic treatment \\ Radiologic treatment \\ Duration of ICU \\ Hospital stay \\ 90-day vital status
}

Abbreviations: CCR completeness of cytoreduction, CRS cytoreductive surgery, CTCAE Common Terminology Criteria for Adverse Events, HIPEC Hyperthermic Intraperitoneal Chemotherapy, ICU Intensive Care Unit, PCI Peritoneal Cancer Index, PIPAC pressurized intraperitoneal aerosol chemotherapy

clinical trials, yet are important for patients information and for clinical decision-makers [51] because they offer the opportunity to assess the feasibility of clinical trials, to facilitate the planning of appropriate clinical trials and to support the enrolment of patients. Because of its nonexperimental design (i.e., no randomization), the present registry can be used to examine the impact of physician practice behaviors on quality of care.

The RENAPE Registry is based upon the voluntary participation of the centers, the percentage of institutions participating is high with all HIPEC French centers including international expert teams members of the Peritoneal Surface Oncology Group International (PSOGI). Unparticipating centers are usually low-volume centers, so that our data are likely skewed towards management practices that are mostly used in larger-volume centers. Therefore the RENAPE Registry is to be considered as a specialized patient-based registry. It doesn't meet strictly the exhaustiveness criteria required for a nationwide population-based cancer registry. To optimize data quality and exhaustiveness, experienced clinical research resources help the centers to complete the data integrity. One of the main strength of the present registry is that detailed data are recorded to characterize patient clinical and pathological features, their multidisciplinary management and outcomes. Overall more than 500 fields have to be filled-in. The consistent longitudinal collection of patient data facilitates the creation of standards of care and dramatically improves patient outcomes even in the absence of new therapies [52]. Data collected also allow the impact therapeutic strategies and clinical practices to be assessed. Furthermore, the RENAPE registry benefits from the many advantages offered by the $\mathrm{EOL}^{\odot}$ application: privacy and security of the data; flexibility and scalability, simplicity and fast implementation. Therefore, the registry is always in evolution to stick to novel standard of care or classification. The experience and multidisciplinary of active contributors allow to continuously evolve this common tool and clinical, histological items from database are upgraded. The RENAPE network organization has 
Table 3 Histological data

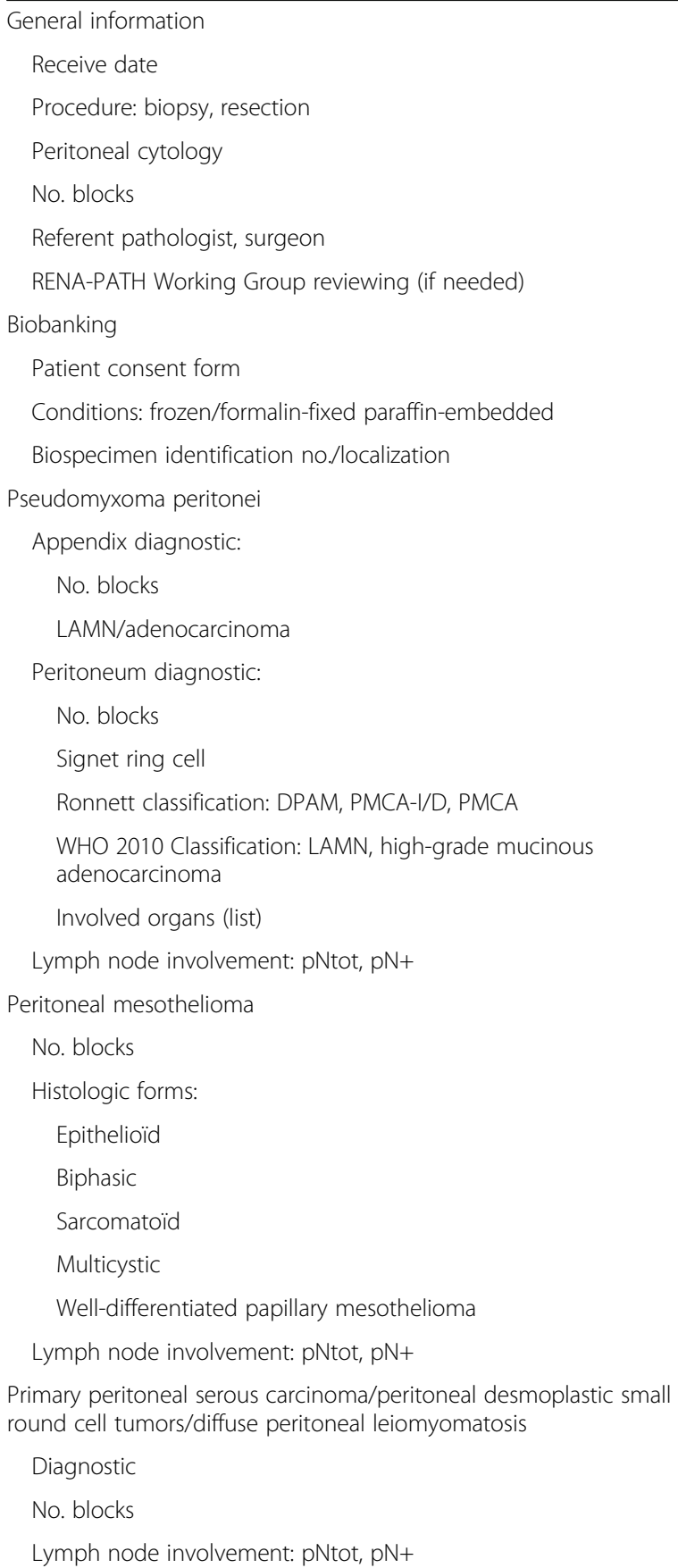

Abbreviations: DPAM disseminated peritoneal adenomucinosis, LAMN low-grade appendiceal mucinous neoplasm, PMCA peritoneal mucinous carcinomatosis, $P M C A-1 / D$ peritoneal mucinous carcinomatosis with intermediate or discordant features, $p N$ tot total number of dissected nodes, $p N+$ number of involved nodes

gathered expert pathologists in the RENA-PATH specialized working group that participate at the process of defining consensus criteria and nomenclature for appendiceal tumors under the auspices of the PSOGI $[7,53]$. The RENA-PATH Group also leads collaborative translational research projects based on the
Table 4 Long term follow-up data

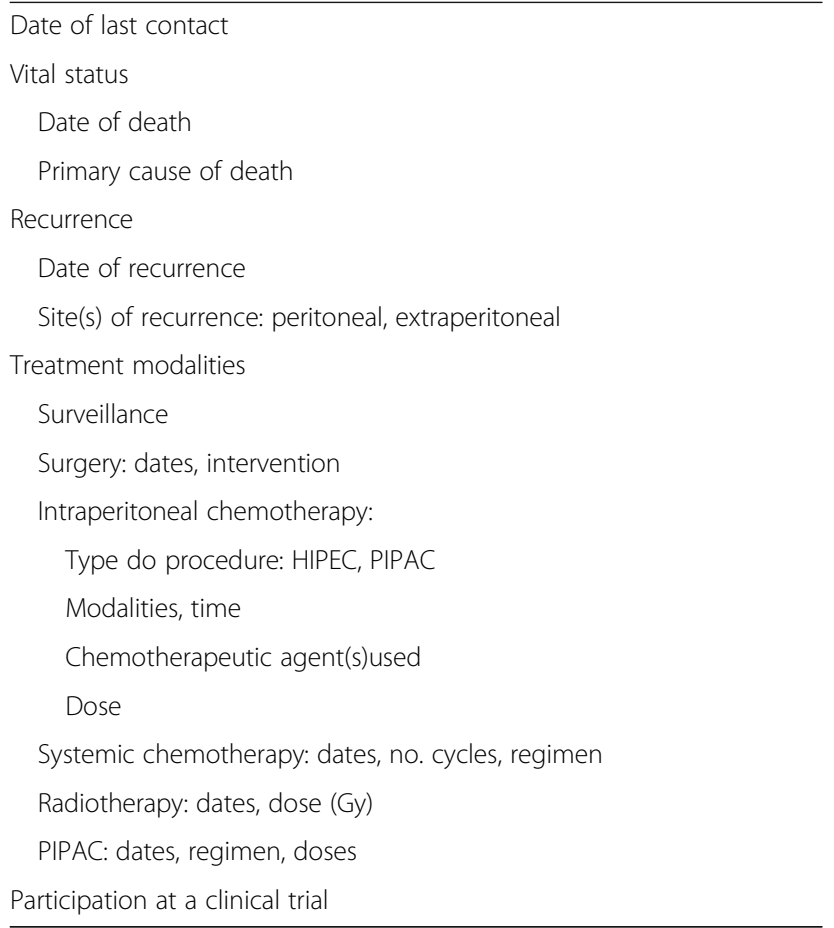

Abbreviation: PIPAC pressurized intraperitoneal aerosol chemotherapy

virtual biobank linked to the Registry clinical database $[54,55]$. Biocollection is disseminated and locally stored in all associated biological resource centers (BSR). In translational collaborative studies, the RENAPE registry is used to screen patient population concerned and to provide survival data. Then analyses are only conducted on available biospecimens for which patients have given their local written consent. The RENA-RAD Working Group has been formed recently with expert radiologists in peritoneal carcinomatosis imaging [56]. They share experiences and develop common tools in order to standardize radiological assessment of patients who are suitable for CRS with HIPEC.

A multidisciplinary care management is required among clinicians, surgeons and experts from the RENAPE network in order to improve patient selection and optimize survival outcomes. Specialists use transversal tools for quantitative and qualitative assessment of patients who are suitable for surgical treatment. The PROMISE ${ }^{\oplus}$ internet application has been developed to allow for a standardized assessment of the peritoneal disease extent intended of multidisciplinary teams and centers that treat patients with RPM [56].

The RENAPE Registry's implementation will clearly rise up to offer the opportunity to fill in important gaps in knowledge about RPM, through national and international collaborations $[9,33,39,53,57,58]$. 


\section{Conclusions}

The rarity of the RPM and their diagnostic uncertainties limit our understanding of its epidemiological features. There is therefore a clear need - recognized by specialists throughout France - for a specific RPM Observational Registry. The information collected from the RENAPE Registry will improve awareness and understanding of the RPM into the incidence, prevalence, recurrence, survival and mortality rates, as well as treatment practices thereby enabling therapeutic intervention to be evaluated and ultimately optimized. The Registry will also enable clinicians to review the prognosis of different patient groups and identify long-term therapeutic benefits of therapeutic interventions. The multi-institutional nature of the project and web-based database structure permit easy data entry and provide a mechanism to scale the RENAPE Registry to a larger consortium of contributing institutions.

\begin{abstract}
Abbreviations
AMARAPE: National patients association against rare peritoneal malignancies; BRCA1: Breast cancer gene one; BSR: Biological resource center; CC score: Completeness of cytoreduction score; CCTIRS: Advisory committee for data processing in health research; CFR: Code of federal regulations; CNIL: French data protection authority; CRS: Cytoreductive surgery; CTCAE: Common terminology criteria for adverse events; DPL: Diffuse peritoneal leiomyomatosis; DSRCT: Desmoplastic small round cell tumor; EOL: Electronic data capture solution designed by Medsharing ${ }^{\oplus}$; EPIRARE: European platform for rare disease registries; ESWR1: Ewing sarcoma breakpoint region 1; GCP: Good clinical practices; HIPEC: Hyperthermic intraperitoneal chemotherapy; INCa: French National Cancer Institute; ITIL: Information technology infrastructure library; LAMN: Low grade appendiceal mucinous neoplasm; PCl: Peritoneal cancer index; PM: Peritoneal mesothelioma; PMP: Pseudomyxoma peritonei; PPSC: Primary peritoneal serous carcinoma; PROMISE: Peritoneal malignancy stage evaluation; PSOGI: Peritoneal surface oncology group international; RENAPE: French network for rare peritoneal tumors; RPM: Rare peritoneal malignancies; SEER: Surveillance, epidemiology and end results; SV: Simian virus; USA: United States of America; WT: Wild type
\end{abstract}

\section{Acknowledgements}

The Clinical Research Unit (Pôle IMER, Hospices Civils de Lyon) has developed the initial MS Access ${ }^{\ominus}$ database which served as the basis for the actual Webdatabase and. It also provides technical support for the data quality control. The members of the RENAPE Network organization which participate to the RENAPE Registry include:

Julio Abba, MD (Department of Digestive Surgery, Grenoble University Hospital, Grenoble, France); Karine Abboud, MD (Department of General Surgery, CHU Hospital, Jean Monnet University, Saint Étienne, France); Mohammad Alyami, MD (Department of Digestive Surgery, Lyon-Sud University Hospital, Lyon, France); Catherine Arvieux, MD, PhD (Department of Digestive Surgery, Grenoble University Hospital, Grenoble, France); Gerlinde Averous, MD (Department of Pathology, Hautepierre University Hospital, Strasbourg, France); Naoual Bakrin, MD, PhD (Department of Digestive Surgery, Lyon-Sud University Hospital, Lyon, France); Gisèle Balagué, MD (Department of Radiology, Claudius Regaud Institute IUTC, Toulouse, France); Vincent Barrau, MD (Department of Radiology, Centre cardiologique du Nord, Saint Denis, France); Houda Ben Rejeb, MD (Department of Pathology, Bergonie Institute, Bordeaux, France); Jean-Marc Bereder, MD, PhD (Department of Digestive Surgery, Archet 2 University Hospital, Nice, France); Isabelle Berton-Rigaud (Department of Digestive Oncology, ICO René Gauducheau Cancer Center, Saint-Herblain, France); Isabelle Bonnefoy (Department of Digestive Surgery, Lyon-Sud University Hospital, Lyon, France); Dominique Bouzard, MD, (Department of Surgery, Louis Mourier University Hospital, Colombes, France); Ivan Bricault, MD, PhD (Department of Radiology, Grenoble University Hospital, Grenoble, France); Cécile Brigand,
MD, PhD (Department of Digestive Surgery, Hautepierre University Hospital, Strasbourg, France); Sébastien Carrère, MD (Department of Surgical Oncology, Val d'Aurelle Montpellier Cancer Center, Montpellier, France); Cécile de Chaisemartin, MD (Department of Surgical Oncology, Paoli Calmettes Institute, Marseille, France); Madleen Chassang, MD (Department of Radiology, Archet 2 University Hospital, Nice, France); Anne Chevallier, MD (Department of Pathology, Archet 2 University Hospital, Nice, France); Thomas Courvoisier, MD (Department of Digestive Surgery, Poitiers University Hospital, Poitiers, France); Peggy Dartigues, MD (Department of Pathology, Gustave Roussy Institute, Villejuif, France); Anthony Dohan, MD, PhD (Department of Radiology, Lariboisière University Hospital, Paris, France); Clarisse Dromain, MD (Department of Radiology, Gustave Roussy Institute, Villejuif, France); Julien Dubreuil, MD, PhD (Department of Radiology, LyonSud University Hospital, Lyon, France); Frédéric Dumont, MD (Department of Surgical Oncology, ICO René Gauducheau Cancer Center, Saint-Herblain, France); Clarisse Eveno, MD, PhD (Surgical Oncologic \& Digestive Unit, Lariboisière University Hospital, Paris, France); Marie Faruch-Bilfeld, MD (Department of Radiology, University Hospital of Toulouse, Toulouse, France); Gwenaël Ferron, MD (Department of Surgical Oncology, Claudius Regaud Institute IUTC, Toulouse, France); Juliette Fontaine, MD (Department of Pathology, Lyon-Sud University Hospital, Lyon, France); Laure Fournier (Department of Radiology, G. Pompidou European Hospital, Paris, France); Johan Gagniere, MD (Department of Digestive Surgery, Estaing University Hospital, Clermont-Ferrand, France); Delphine Geffroy, MD (Department of Radiology, ICO René Gauducheau Cancer Center, Saint-Herblain, France); Laurent Ghouti, MD (Department of Digestive Surgery, Purpan University Hospital, Toulouse, France); Laurence Gladieff (Department of Medical Oncology, Claudius Regaud Institute IUTC, Toulouse, France); Diane Goéré, MD, PhD. (Department of Surgical Oncology, Gustave Roussy Institute, Villejuif, France); Aymeric Guibal, MD (Department of Radiology, Hospital of Perpignan, Perpignan, France); Jean-Marc Guilloit, MD (Department of Surgical Oncology, Francois Baclesse Comprehensive Cancer Center, Caen, France); Frédéric Guyon, MD (Department of Surgical Oncology, Bergonie Institute, Bordeaux, France); Bruno Heyd, MD, PhD (Department of Digestive Surgery, Minjoz University Hospital, Besançon, France); Christine Hoeffel, MD, PhD (Department of Radiology, Robert Debré University Hospital, Reims, France). Constance Hordonneau (Department of Radiology, Montpied University Hospital, Clermont-Ferrand, France); Peggy Jourdan-Enfer (Department of Digestive Surgery, Lyon-Sud University Hospital, Lyon, France); Rachid Kaci, MD (Department of Pathology, Lariboisière University Hospital, Paris, France); Reza Kianmanesh (Department of Digestive Surgery, Robert Debré University Hospital, Reims, France); Catherine Labbé-Devilliers, MD (Department of Radiology, ICO René Gauducheau Cancer Center, SaintHerblain, France); Joëlle Lacroix, MD (Department of Radiology, Francois Baclesse Comprehensive Cancer Center, Caen, France); Bernard Lelong, MD (Department of Surgical Oncology, Paoli Calmettes Institute, Marseille, France); Agnès Leroux-Broussier, MD (Department of Pathology, Lorraine Institute of Oncology, Vandoeuvre-les-Nancy, France); Yoann Lherm (Hospices Civils de Lyon, Pôle Information Médicale Evaluation Recherche, Unité de Recherche Clinique, Lyon, France); Réa Lo Dico, MD (Surgical Oncologic \& Digestive Unit, Lariboisière University Hospital, Paris, France); Gérard Lorimier, MD (Department of Digestive Surgery, Angers University Hospital, Angers, France); Caroline Malhaire, MD (Department of Radiology, Curie Institute, Paris, France); Frédéric Marchal, MD, PhD (Department of Surgical Oncology, Lorraine Institute of Oncology, Vandoeuvre-les-Nancy, France); Pascale Mariani, MD (Department of Surgical Oncology, Curie Institute, Paris, France); Emilie Mathiotte (Hospices Civils de Lyon, Pôle Information Médicale Evaluation Recherche, Unité de Recherche Clinique, Lyon, France); Pierre Meeus, MD (Department of Surgery, Léon Bérard Comprehensive Cancer Center, Lyon, France); Eliane Mery, MD (Department of Pathology, Claudius Regaud Institute IUTC, Toulouse, France); Simon Msika, MD, PhD (Department of Surgery, Louis Mourier University Hospital, Colombes, France); Cédric Nadeau, MD (Gynaecology and Obstetrics Ward, Mother and Child Pole, Poitiers University Hospital, University of Poitiers, Poitiers, France); Pablo Ortega-Deballon, MD, PhD (Department of Digestive Surgical Oncology, University Hospital of Dijon, Dijon, France); Olivier Pellet, MD (INOLA, Lyon, France); Patrice Peyrat, MD (Department of Surgery, Léon Bérard Comprehensive Cancer Center, Lyon, France); Denis Pezet, MD, PhD (Department of Digestive Surgery, Estaing University Hospital, Clermont-Ferrand, France); Nicolas Pirro, MD, PhD (Department of Digestive Surgery, Timône University Hospital, Marseille, 
France); Marc Pocard, MD, PhD (Surgical Oncologic \& Digestive Unit, Lariboisière University Hospital, Paris, France); Flora Poizat, MD (Department of Pathology, Paoli Calmettes Institute, Marseille, France); Jack Porcheron, MD, PhD (Department of Digestive Surgery, St Etienne University Hospital, St Etienne, France); Anaïs Poulet, PhD (Department of Digestive

Surgery, Lyon-Sud University Hospital, Lyon, France); François Quenet, MD (Department of Surgical Oncology, Val d'Aurelle Montpellier Cancer Center, Montpellier, France); Patrick Rat, MD, PhD (Department of Digestive Surgical Oncology, University Hospital of Dijon, Dijon, France); Pierre Rousselot, MD (Department of Pathology, Francois Baclesse Comprehensive Cancer Center, Caen, France); Hélène Senellart (Department of Medical Oncology, ICO René Gauducheau Cancer Center, Saint-Herblain, France); Martine Serrano (Department of Digestive Surgery, Lyon-Sud University Hospital, Lyon, France); Vincent Servois, MD (Department of Radiology, Curie Institute, Paris, France); Olivia Sgabura MD (Department of Surgical Oncology, Val d'Aurelle Montpellier Cancer Center, Montpellier, France); Andrea Skanjeti, MD (Department of Radiology, Lyon-Sud University Hospital, Lyon, France); Magali Svrcek, MD, PhD (Department of Pathology, Hospital Saint-Antoine AP-HP, Paris, France); Raphaël Tetreau, MD, (Department of Radiology, Val d'Aurelle Montpellier Cancer Center, Montpellier, France); Emilie Thibaudeau, MD (Department of Surgical Oncology, ICO René Gauducheau Cancer Center, Saint-Herblain, France); Yann Touchefeu (Department of Gastroenterology, Nantes University Hospital, Nantes); JeanJacques Tuech, MD, PhD (Department of Digestive Surgery, Charles Nicolle University Hospital, Rouen, France); Séverine Valmary-Degano, MD, PhD (Department of Pathology, Minjoz University Hospital, Besançon, France); Delphine Vaudoyer, MD (Department of Digestive Surgery, Lyon-Sud University Hospital, Lyon, France); Stéphane Velasco, MD (Department of Radiology, Poitiers University Hospital, Poitiers, France); Véronique Verriele-Beurrier, MD (Department of Pathology, ICO Paul Papin Cancer Center, Angers, France); Romuald Wernert, MD (Department of Surgical Oncology, ICO Paul Papin Cancer Center, Angers, France); Franck Zinzindohoue, MD, PhD (Department of Digestive and General Surgery, G. Pompidou European Hospital, Paris, France).

\section{Funding}

The RENAPE Registry was established with the support of the French National Cancer Institute (INCa) in order to meet the action 23.1 "Certify rare cancer reference centers" of the 2009-2013 French Cancer Control Plan devoted to rare cancers.

\section{Availability of data materials}

Not applicable.

\section{Author's contributions}

All persons who meet authorship criteria are listed as authors, and all authors certify that they have participated sufficiently in the work to take public responsibility for the content, including participation in the concept, design, writing, or revision of the manuscript. Furthermore, each author certifies that this material or similar material has not been and will not be submitted to or published in any other publication before. Conception and design of the registry: LV, GP, OG, SI, FB, PR, FNG. Acquisition of data: LV, GP, $\mathrm{OG}, \mathrm{SI}, \mathrm{FB}, \mathrm{PR}$. Interpretation of data: LV, GP, OG, SI, FB, PR, FNG. Drafting the manuscript: LV, GP, OG, SI, FB, PR. Revising the manuscript critically for important intellectual content: LV, GP, OG, SI, FB, PR, FNG. Approval of the version of the manuscript to be published: LV, GP, OG, SI, FB, PR, FNG. All authors read and approved the final manuscript.

\section{Author's information}

LV coordinates the French National Network for the Treatment of Rare Peritoneal Surface Malignancies (RENAPE); FNG is the Scientific Director of the RENAPE Reference Network; OG is head of the Lyon Expert Centre in the management of rare peritoneal surface malignancies (Centre Hospitalier Lyon, France, Hospices Civils de Lyon).

\section{Competing interests}

The authors declare that they have no competing interests.

\section{Consent for publication}

Not applicable.

\section{Ethics approval and consent to participate}

Not applicable.

\author{
Author details \\ ${ }^{1}$ Hospices Civils de Lyon, Pôle Information Médicale Evaluation Recherche, \\ Unité de Recherche Clinique, Lyon, France. ²EMR 3738, Lyon 1 University, \\ Lyon, France. ${ }^{3}$ Department of Digestive Surgery, Centre Hospitalier Lyon Sud, \\ Pierre-Bénite, France. ${ }^{4}$ Department of Pathology, Centre Hospitalier Lyon Sud, \\ Pierre-Bénite, France. ${ }^{5}$ Department of Pathology, Centre Hospitalier \\ Universitaire, Caen, France. ${ }^{6}$ Department of Radiology, Centre Hospitalier \\ Lyon Sud, Pierre-Bénite, France. ${ }^{7}$ RENAPE, Hospices Civils de Lyon, Centre \\ Hospitalier Lyon Sud, 165 Chemin du Grand Revoyet, 69495 Pierre-Bénite, \\ France.
}

Received: 31 October 2016 Accepted: 13 January 2017 Published online: 17 February 2017

\section{References}

1. Zhong $Y$, Deng $M, X u R$, et al. Pseudomyxoma peritonei as an intractable disease and its preoperative assessment to help improve prognosis after surgery: a review of the literature. Intractable Rare Dis Res. 2012;1:115-21.

2. Smeenk RM, van Velthuysen ML, Verwaal VJ, Zoetmulder FA. Appendiceal neoplasms and pseudomyxoma peritonei: a population based study. Eur J Surg Oncol. 2008;34:196-201.

3. Sugarbaker PH, Ronnett BM, Archer A, et al. Pseudomyxoma peritonei syndrome. Adv Surg. 1996:30:233-80.

4. Mann Jr WJ, Wagner J, Chumas J, Chalas E. The management of pseudomyxoma peritonei. Cancer. 1990;66:1636-40.

5. Dartigues $P$, Isaac $S$, Villeneuve $L$, et al. Peritoneal pseudomyxoma: an overview emphasizing pathological assessment and therapeutic strategies. Ann Pathol. 2014;34:14-25.

6. Taflampas P, Dayal S, Chandrakumaran K, et al. Pre-operative tumour marker status predicts recurrence and survival after complete cytoreduction and hyperthermic intraperitoneal chemotherapy for appendiceal Pseudomyxoma Peritonei: Analysis of 519 patients. Eur J Surg Oncol. 2014; 40:515-20.

7. Misdraji J. Mucinous epithelial neoplasms of the appendix and pseudomyxoma peritonei. Mod Pathol. 2015;28 Suppl 1:S67-79.

8. Bosmann FT, Carneiro F, Hruban RH, Theise ND. WHO classification of tumours of the digestive system. Lyon: IARC; 2010.

9. Chua TC, Moran BJ, Sugarbaker PH, et al. Early- and long-term outcome data of patients with pseudomyxoma peritonei from appendiceal origin treated by a strategy of cytoreductive surgery and hyperthermic intraperitoneal chemotherapy. J Clin Oncol. 2012;30:2449-56.

10. Spiliotis J, Halkia E, de Bree E. Treatment of peritoneal surface malignancies with hyperthermic intraperitoneal chemotherapy-current perspectives. Curr Oncol. 2016;23:e266-275.

11. Bevan KE, Mohamed F, Moran BJ. Pseudomyxoma peritonei. World J Gastrointest Oncol. 2010;2:44-50.

12. Chua TC, Yan TD, Smigielski ME, et al. Long-term survival in patients with pseudomyxoma peritonei treated with cytoreductive surgery and perioperative intraperitoneal chemotherapy: 10 years of experience from a single institution. Ann Surg Oncol. 2009;16:1903-11.

13. Sugarbaker $\mathrm{PH}$, Chang D. Results of treatment of 385 patients with peritoneal surface spread of appendiceal malignancy. Ann Surg Oncol. 1999; 6:727-31.

14. Youssef $\mathrm{H}$, Newman C, Chandrakumaran $\mathrm{K}$, et al. Operative findings, early complications, and long-term survival in 456 patients with pseudomyxoma peritonei syndrome of appendiceal origin. Dis Colon Rectum. 2011:54:293-9.

15. Elias D, Honore C, Ciuchendea R, et al. Peritoneal pseudomyxoma: results of a systematic policy of complete cytoreductive surgery and hyperthermic intraperitoneal chemotherapy. Br J Surg. 2008;95:1164-71.

16. Boffetta P. Epidemiology of peritoneal mesothelioma: a review. Ann Oncol. 2007;18:985-90.

17. Hassan R, Alexander R. Nonpleural mesotheliomas: mesothelioma of the peritoneum, tunica vaginalis, and pericardium. Hematol Oncol Clin North Am. 2005;19:1067-87. vi.

18. Taub RN, Keohan ML, Chabot JC, et al. Peritoneal mesothelioma. Curr Treat Options Oncol. 2000;1:303-12.

19. Mery E, Hommell-Fontaine J, Capovilla M, et al. Peritoneal malignant mesothelioma: review and recent data. Ann Pathol. 2014;34:26-33. 
20. Acherman YI, Welch LS, Bromley CM, Sugarbaker PH. Clinical presentation of peritoneal mesothelioma. Tumori. 2003;89:269-73.

21. Welch LS, Acherman YI, Haile E, et al. Asbestos and peritoneal mesothelioma among college-educated men. Int J Occup Environ Health. 2005;11:254-8

22. Yan TD, Welch $L$, Black D, Sugarbaker PH. A systematic review on the efficacy of cytoreductive surgery combined with perioperative intraperitoneal chemotherapy for diffuse malignancy peritoneal mesothelioma. Ann Oncol. 2007;18:827-34.

23. Chahinian AP, Pajak TF, Holland JF, et al. Diffuse malignant mesothelioma. Prospective evaluation of 69 patients. Ann Intern Med. 1982;96:746-55.

24. Peterson Jr JT, Greenberg SD, Buffler PA. Non-asbestos-related malignant mesothelioma. A review Cancer. 1984;54:951-60.

25. Riddell RH, Goodman MJ, Moossa AR. Peritoneal malignant mesothelioma in a patient with recurrent peritonitis. Cancer. 1981;48:134-9.

26. Husain AN, Colby TV, Ordonez NG, et al. Guidelines for pathologic diagnosis of malignant mesothelioma: a consensus statement from the International Mesothelioma Interest Group. Arch Pathol Lab Med. 2009;133:1317-31.

27. Baratti D, Kusamura S, Nonaka D, et al. Multicystic and well-differentiated papillary peritoneal mesothelioma treated by surgical cytoreduction and hyperthermic intra-peritoneal chemotherapy (HIPEC). Ann Surg Oncol. 2007; 14:2790-7.

28. Baratti D, Kusamura S, Sironi A, et al. Multicystic peritoneal mesothelioma treated by surgical cytoreduction and hyperthermic intra-peritoneal chemotherapy (HIPEC). In Vivo. 2008;22:153-7.

29. Baratti D, Vaira M, Kusamura S, et al. Multicystic peritoneal mesothelioma: outcomes and patho-biological features in a multi-institutional series treated by cytoreductive surgery and Hyperthermic Intraperitoneal Chemotherapy (HIPEC). Eur J Surg Oncol. 2010;36:1047-53.

30. Feldman AL, Libutti SK, Pingpank JF, et al. Analysis of factors associated with outcome in patients with malignant peritoneal mesothelioma undergoing surgical debulking and intraperitoneal chemotherapy. J Clin Oncol. 2003;21: 4560-7.

31. Passot G, Cotte $\mathrm{E}$, Brigand $\mathrm{C}$, et al. Peritoneal mesothelioma: treatment with cytoreductive surgery combined with hyperthermic intraperitoneal chemotherapy. J Chir (Paris). 2008;145:447-53.

32. Kepenekian V, Elias D, Passot G, et al. Diffuse malignant peritoneal mesothelioma: evaluation of systemic chemotherapy with comprehensive treatment through the RENAPE database: multi-institutional retrospective study. Eur J Cancer. 2016;65:69-79.

33. Yan TD, Deraco M, Baratti $D$, et al. Cytoreductive surgery and hyperthermic intraperitoneal chemotherapy for malignant peritoneal mesothelioma: multi-institutional experience. J Clin Oncol. 2009;27:6237-42.

34. Grant DJ, Moorman PG, Akushevich L, et al. Primary peritoneal and ovarian cancers: an epidemiological comparative analysis. Cancer Causes Control. 2010;21:991-8.

35. Schorge JO, Muto MG, Lee SJ, et al. BRCA1-related papillary serous carcinoma of the peritoneum has a unique molecular pathogenesis. Cancer Res. 2000;60:1361-4.

36. Schorge JO, Muto MG, Welch WR, et al. Molecular evidence for multifocal papillary serous carcinoma of the peritoneum in patients with germline BRCA1 mutations. J Natl Cancer Inst. 1998;90:841-5.

37. Bakrin N, Gilly FN, Baratti D, et al. Primary peritoneal serous carcinoma treated by cytoreductive surgery combined with hyperthermic intraperitoneal chemotherapy. A multi-institutional study of 36 patients. Eur J Surg Oncol. 2013;39:742-7.

38. Gerald WL, Miller HK, Battifora H, et al. Intra-abdominal desmoplastic small round-cell tumor. Report of 19 cases of a distinctive type of high-grade polyphenotypic malignancy affecting young individuals. Am J Surg Pathol. 1991;15:499-513.

39. Honore C, Amroun $\mathrm{K}$, Vilcot $\mathrm{L}$, et al. Abdominal desmoplastic small round cell tumor: multimodal treatment combining chemotherapy, surgery, and radiotherapy is the best option. Ann Surg Oncol. 2015;22:1073-9.

40. Lettieri CK, Garcia-Filion P, Hingorani P. Incidence and outcomes of desmoplastic small round cell tumor: results from the surveillance, epidemiology, and end results database. J Cancer Epidemiol. 2014;2014: 680126

41. Wong $\mathrm{HH}$, Hatcher HM, Benson $\mathrm{C}$, et al. Desmoplastic small round cell tumour: characteristics and prognostic factors of 41 patients and review of the literature. Clin Sarcoma Res. 2013;3:14.
42. Ladanyi M, Gerald W. Fusion of the EWS and WT1 genes in the desmoplastic small round cell tumor. Cancer Res. 1994;54:2837-40.

43. Lausen I, Jensen O, Andersen E, Lindahl F. Disseminated peritoneal leiomyomatosis with malignant change, in a male. Vichows Archiv A Pathol Anat. 1990;417:173-5.

44. Yamaguchi T, Imamura Y, Yamamoto T, Fukuda M. Leiomyomatosis peritonealis disseminata with malignant change in a man. Pathol Int. 2003; 53:179-85.

45. Bourgain RH, Paubert-Braquet M, Shen S, et al. An optoelectronic registration method as applied to PAF-mediated hydrogen peroxide induced arterial thrombosis. J Lipid Mediat Cell Signal. 1994;9:79-88.

46. Tavassoli FA, Norris HJ. Peritoneal leiomyomatosis (leiomyomatosis peritonealis disseminata): a clinicopathologic study of 20 cases with ultrastructural observations. Int J Gynecol Pathol. 1982;1:59-74.

47. Kratz KG, Santillan A, Gu M, Bristow RE. Radical surgical cytoreduction of progressive leiomyomatosis peritonealis disseminata: a case report. J Reprod Med. 2009;54:447-50.

48. Villeneuve $L$, Isaac $S$, Glehen $\mathrm{O}$, et al. The RENAPE network: towards a new healthcare organization for the treatment of rare tumors of the peritoneum. Description of the network and role of the pathologists. Ann Pathol. 2014; 34:4-8.

49. Agency for Healthcare Research and Quality. Registries for evaluating patient outcomes: a user's guide. Rockville: AHRQ Publication No. 13(14)-EHC111; 2014

50. Guidance for Industry Part 11, Electronic records; electronic signatures scope and application. In Services USDoHaH (ed). Food and Drug Administration August: 2003

51. Dreyer NA, Garner S. Registries for robust evidence. JAMA. 2009;302:790-1.

52. EURORDIS, NORD, CORD. Joint declaration of 10 key principles for rare disease patient registries. 2012.

53. Carr NJ, Cecil TD, Mohamed F, et al. A consensus for classification and pathologic reporting of pseudomyxoma peritonei and associated appendiceal neoplasia: the results of the peritoneal surface oncology group international (PSOGI) modified delphi process. Am J Surg Pathol. 2016;40: 14-26.

54. Chirac P, Maillet D, Lepretre F, et al. Genomic copy number alterations in 33 malignant peritoneal mesothelioma analyzed by comparative genomic hybridization array. Hum Pathol. 2016;55:72-82.

55. Hommell-Fontaine J, Isaac S, Passot G, et al. Malignant peritoneal mesothelioma treated by cytoreductive surgery and hyperthermic intraperitoneal chemotherapy: is GLUT1 expression a major prognostic factor? A preliminary study. Ann Surg Oncol. 2013;20:3892-8.

56. Villeneuve $L$, Thivolet $A$, Bakrin $N$, et al. A new internet tool to report peritoneal malignancy extent. PeRitOneal malignancy stage evaluation (PROMISE) application. Eur J Surg Oncol. 2016;42:877-82.

57. Carr NJ. Current concepts in pseudomyxoma peritonei. Ann Pathol. 2014;34:9-13.

58. Yan TD, Deraco M, Elias D, et al. A novel tumor-node-metastasis (TNM) staging system of diffuse malignant peritoneal mesothelioma using outcome analysis of a multi-institutional database*. Cancer. 2011;117: 1855-63.

\section{Submit your next manuscript to BioMed Central and we will help you at every step:}

- We accept pre-submission inquiries

- Our selector tool helps you to find the most relevant journal

- We provide round the clock customer support

- Convenient online submission

- Thorough peer review

- Inclusion in PubMed and all major indexing services

- Maximum visibility for your research

Submit your manuscript at www.biomedcentral.com/submit 